\title{
Chiral Separation of Lactic Acid in Culture Media and Cells of Lactobacillus delbrueckii subsp. lactis as $O$-Pentafluoropropionylated (S)-(+)-3-Methyl-2-Butyl Ester by Achiral Gas Chromatography-Mass Spectrometry
}

\author{
Man-Jeong Paik, ${ }^{\dagger}$ Duc-Toan Nguyen, ${ }^{\dagger}$ Jaehwan Yoon,,${ }^{\dagger}$ Han Seung Chae, ${ }^{\dagger}$ \\ Kyoung-Rae Kim, ${ }^{\dagger}$ Gwang Lee, ${ }^{\dagger, \$, a}$ and Pyung Cheon Lee ${ }^{\dagger, *}$ \\ †Department of Molecular Science and Technology, Ajou University, Suwon 443-749, Korea. "E-mail: pclee@ajou.ac.kr \\ ${ }^{\sharp}$ Biometabolite Analysis Laboratory, College of Pharmacy, Sungkyunkwan University, Suwon 440-746, Korea \\ ${ }^{\S}$ Institute for Medical Science, School of Medicine, Ajou University, Suwon 443-721, Korea \\ Received February 26, 2011, Accepted June 9, 2011
}

\begin{abstract}
The enantiomeric separation of lactic acid for its absolute configuration has become important task for understanding its biological origin and metabolic process involved in the formation of lactic acid. It involves the conversion of enantiomers as diastereomeric $O$-pentafluoropropionylated $(S)-(+)-3$-methyl-2-butyl ester and the direct separation by gas chromatography-mass spectrometry on a achiral capillary column. The $(R)-$ and $(S)$-lactic acids were completely separated with a high resolution of 1.9. The newly developed method showed good linearity $(r \geq 0.999)$, precision (\% relative standard deviation $=3.4-6.2)$, and accuracy $(\%$ relative error $=-7.7-1.4)$ with the detection limit of $0.011 \mu \mathrm{g} / \mathrm{mL}$. When the method was applied to determine the absolute configuration of lactic acid in Lactobacillus delbrueckii subsp. lactis 304 (LAB 304), the composition $(\%)$ of $(R)$-lactic acid in the cell pellet and in the culture medium were $89.0 \pm 0.1$ and $78.2 \pm 0.4$, respectively. Thus, it was verified that the present method is useful for the identification and composition test of lactic enantiomers in microorganisms.
\end{abstract}

Key Words : Chiral separation, Lactic acid, Diastereomeric $O$-pentafluoropropionylated $(S)-(+)-3$-methyl-2butyl ester, Achiral gas chromatography-mass spectrometry, Lactobacillus delbrueckii subsp. lactis 304

\section{Introduction}

Lactic acid as chiral organic acid is widely used in food, pharmaceutical, and chemical industries. ${ }^{1-5}$ Recently, an accurate measurement for the optical purity of lactic acids has been known as important factor of the physical property in the fermentation process. Therefore, the separation of lactic acid enantiomers has become an important task in the evaluation of enhanced microbial productivity.

Various analytical methods for the chiral separation of lactic acid by using gas chromatography (GC) ${ }^{6,7} \mathrm{GC}$-mass spectrometry (MS), ${ }^{1,8}, 9$ high-performance liquid chromatography (HPLC), ${ }^{2,3,10}$ LC-MS ${ }^{11,12}$ and capillary electrophoresis ${ }^{13,14}$ were reported in the literatures.

Previously, we reported two chiral separation methods of organic acids including lactic acid, which based on the conversion of each enantiomer into as diastereomeric $O$ trifluoroacetylated-(S)-(+)-3-methyl-2-butyl ester ${ }^{6}$ and $O$ trifluoroacetylated-(-)-menthyl ester ${ }^{7}$ by using achiral GC.

Recently, GC combined with MS has been widely used for peak identification and quantification of various samples.

Therefore, this study was intended to complement and improvement for our previous chiral separation methods of lactic ${ }^{6,7}$ by using achiral GC-MS in selected ion monitoring (SIM) mode following conversion each enantiomer of lactic acid into diastereomeric derivative with better MS property

${ }^{a}$ co-corresponding author. than those of previous our methods.

In the first reaction, the carboxyl group of lactic acid was converted into diastereomeric $(S)-(+)-3$-methyl-2-butyl ester by using $(S)-(+)-3$-methyl-2-butanol as the chiral reagent. And in the second step, remained the hydroxyl group was converted into a pentafluoropropionyl (PFP) derivative with pentafluoropropionic anhydride (PFPA).

This new method was optimized and then used to carry out enantiomeric composition tests after identification of lactic acid by GC-MS in the cells and media of microorganisms as our previous organic acid profiling method using tert-butyldimethylsilyl (TBDMS) derivative. ${ }^{15-17}$

\section{Experimental}

Chemicals and Reagents. Racemic lactic acid, $(S)$-lactic acid, 3,4-dimethoxybenzoic acid ( $\left.\mathrm{IS}_{1}\right)$ and $n$-docosane $\left(\mathrm{IS}_{2}\right)$ as internal standards (ISs), $(S)-(+)-3$-methyl-2-butanol, PFPA, and acetyl chloride were obtained from Sigma-Aldrich (St. Louis, MO, USA). $N$-Methyl- $N$-(tert-butyldimethylsilyl)trifluoroacetamide (MTBSTFA) as silylating reagent was purchased from Pierce (Rockford, IL, USA). Acetonitrile, toluene, diethyl ether, ethyl acetate, and dichloromethane of PCB grade were purchased from Kanto (Tokyo, Japan). And sulfuric acid was obtained from Songyawon (Osaka, Japan). All the chemicals were of analytical grade and were used as received.

Microorganism and Growth Condition. Lactobacillus 
delbrueckii subsp. lactis 304 (LAB 304) was anaerobically grown in MRS medium supplemented of $100 \mathrm{~mL}$ with $0.1 \%$ $\mathrm{CaCO}_{3}$, and the temperature was maintained at $37{ }^{\circ} \mathrm{C}$ for 24 $\mathrm{h}$ until $\mathrm{OD}_{600}$ of $0.4-0.6$. The culture supernatant was transferred to a test tube after the culture medium was centrifuged at $4000 \mathrm{rpm}$ for $10 \mathrm{~min}$. The cell pellet was washed with saline (x 3), which was resuspended in distilled water of $0.5 \mathrm{~mL}$.

Preparation of Standards and Calibration Solutions. The stock standard solutions of racemic lactic acid and $(S)$ lactic acid were made up at $10 \mu \mathrm{g} / \mathrm{mL}$ in acetonitrile. Solutions of $\mathrm{IS}_{1}$ and $\mathrm{IS}_{2}$ were dissolved at $1.0 \mu \mathrm{g} / \mathrm{mL}$ in acetonitrile and toluene, respectively. Then, the working solutions of racemic lactic acid and $(S)$-lactic acid were prepared as $50 \mathrm{ng} / \mu \mathrm{L}$ in acetonitrile. Working solutions of $\mathrm{IS}_{1}$ and $\mathrm{IS}_{2}$ were prepared as $100 \mathrm{ng} / \mu \mathrm{L}$ in acetonitrile and toluene, respectively. Seven calibration samples containing $(S)$-lactic acid and $(R)$-lactic acid in the range 0.1-15.0 $\mu \mathrm{g}$ were prepared. All the standard solutions were stored at 4 ${ }^{\circ} \mathrm{C}$.

Gas Chromatography-Mass Spectrometry. The temperatures of the injector, interface, and ion source were 260, 300 and $230{ }^{\circ} \mathrm{C}$, respectively. The samples were introduced into the split-injection mode $(10: 1)$. The oven temperature was maintained at $80^{\circ} \mathrm{C}(1 \mathrm{~min})$, and this temperature was increased to $100{ }^{\circ} \mathrm{C}$ at $5{ }^{\circ} \mathrm{C} / \mathrm{min}$ and finally to $300^{\circ} \mathrm{C}(5 \mathrm{~min})$ at the rate of $30^{\circ} \mathrm{C} / \mathrm{min}$. GC-MS analysis in SIM mode was performed using an Agilent 6890N gas chromatograph interfaced with an Agilent 5975B mass-selective detector $(70 \mathrm{eV}$, electron impact mode) and installed with an Ultra-2 crosslinked capillary column (5\% phenyl-95\% methylpolysiloxane bonded phase; $25 \mathrm{~m} \times 0.20 \mathrm{~mm}$ I.D., $0.11 \mu \mathrm{m}$ film thickness) (Agilent Technologies, Atlanta, GA, USA). In characteristic SIM ions showed in Table 1. All GC-MS-SIM analyses were performed in triplicate.

Diastereomeric $(S)-(+)-3-M e t h y l-2-B u t y l a t i o n$ and $\boldsymbol{O}$ Pentafluoropropionylation. First, a mixture of racemic lactic acid $(10 \mu \mathrm{g}),(S)$-lactic acid $(10 \mu \mathrm{g})$, and $\mathrm{IS}_{2}(8 \mu \mathrm{g})$ were evaporated under a gentle nitrogen stream at $40{ }^{\circ} \mathrm{C}$. Next, toluene $(20 \mu \mathrm{L}),(S)-(+)-3$-methyl-2-butanol $(20 \mu \mathrm{L})$, and acetyl chloride $(1 \mu \mathrm{L})$ were added to the dry residue.
Then, the resulting mixture solution was reacted at $100{ }^{\circ} \mathrm{C}$ for $1 \mathrm{~h}$ for conversion as diastereomer esters. Next, it was evaporated under a gentle nitrogen stream in order to remove excess reagent, which was reacted with PFPA $(20 \mu \mathrm{L})$ in ethyl acetate $(10 \mu \mathrm{L})$ at $60{ }^{\circ} \mathrm{C}$ for $30 \mathrm{~min}$. Finally, after evaporation, the reaction mixture was dissolved in toluene $(30 \mu \mathrm{L})$ and was analyzed by GC-MS in SIM mode.

Method Validation. The method validation for measurement of $(R)$-lactic acid and $(S)$-lactic acid was performed by using seven calibration racemic samples $(0.2,0.5,1.0,2.0$, $5.0,10.0$, and $30.0 \mu \mathrm{g}$ ) and an $\mathrm{IS}_{2}$ of $8 \mu \mathrm{g}$. The linearity for each enantiomer of lactic acid was measured at the range of $0.1-15.0 \mu \mathrm{g}$ by performing least-squares regression analysis. The precision and accuracy were expressed as the percentage of the relative standard deviation (\% RSD) and as the percentage of the relative error (\% RE), respectively. The limit of detection (LOD) and limit of quantification (LOQ) were calculated as the lowest concentration giving a signal greater than the sum of the mean blank signal plus three and 10 times the standard deviation of the blank signal, respectively. They were obtained for three blank measurements.

Sample Preparation of Lactic Acid in LAB 304 Cells and Cell Growth Media as Racemic TBDMS Derivative. 3,4-Dimethoxybenzoic as $\mathrm{IS}_{1}$ was added to each aliquot of the cell after freeze-thaw lysis and to the supernatant of the growth media, respectively. The $\mathrm{pH}$ was adjusted to be less than or equal to 2 by adding concentrated sulfuric acid and saturated with sodium chloride. Then, they were extracted using diethyl ether $(3 \mathrm{~mL})$ and ethyl acetate $(2 \mathrm{~mL})$, which were dried by evaporation (under a gentle stream of nitrogen) and added to TEA $(5 \mu \mathrm{L})$ and toluene $(10 \mu \mathrm{L})$. The resulting mixture was then reacted with MTBSTFA $(10 \mu \mathrm{L})$ at $60{ }^{\circ} \mathrm{C}$ for $30 \mathrm{~min}$ to form TBDMS derivative. Finally, the reaction mixtures were analyzed by GC-MS as our previous methods. ${ }^{15-17}$

Sample Preparation for Chiral Separation of Lactic Acid in LAB 304 Cells and Cell Growth Media. Docosane as $\mathrm{IS}_{2}$ was added to aliquot of the cell after freeze-thaw lysis and to the supernatant of the growth media, respectively. The $\mathrm{pH}$ was adjusted to be less than or equal to 2 by adding concentrated sulfuric acid and saturated with sodium chloride.

Table 1. Validation data for the measurement of lactic acid enantiomers as $O$-pentafluoropropionylated $(S)-(+)-3$-methyl-2-butyl ester by GC-SIM-MS

\begin{tabular}{|c|c|c|c|c|c|c|c|c|c|}
\hline Enantiomer & $\begin{array}{l}\text { Selected } \\
\text { ion }(m / z)\end{array}$ & $\begin{array}{l}\text { Resolution } \\
\quad(\mathrm{Rs})^{a}\end{array}$ & $\begin{array}{c}\text { Calibration } \\
\text { range }(\mu \mathrm{g} / \mathrm{mL})^{b}\end{array}$ & $\begin{array}{c}\text { Linearity }^{c} \\
r\end{array}$ & $\begin{array}{c}\text { LOD } \\
(\mu \mathrm{g} / \mathrm{mL})^{d}\end{array}$ & $\begin{array}{c}\text { LOQ } \\
(\mu \mathrm{g} / \mathrm{mL})^{e}\end{array}$ & $\begin{array}{l}\text { Added } \\
(\mu \mathrm{g} / \mathrm{mL})\end{array}$ & $\begin{array}{l}\text { Precision } \\
(\% \text { RSD })^{f}\end{array}$ & $\begin{array}{l}\text { Accuracy } \\
(\% \mathrm{RE})^{g}\end{array}$ \\
\hline \multirow{3}{*}{$(R)$-Lactic acid } & \multirow{3}{*}{$\mathbf{1 9 1}, 219,291$} & \multirow{3}{*}{1.9} & \multirow{3}{*}{$0.1-15.0$} & \multirow{3}{*}{0.999} & \multirow{3}{*}{0.011} & \multirow{3}{*}{0.036} & 0.25 & 3.5 & -5.3 \\
\hline & & & & & & & 1.0 & 6.0 & -0.4 \\
\hline & & & & & & & 2.5 & 3.4 & 0.1 \\
\hline \multirow{3}{*}{$(S)$-Lactic acid } & \multirow{3}{*}{$\mathbf{1 9 1}, 219,291$} & & \multirow{3}{*}{$0.1-15.0$} & \multirow{3}{*}{0.999} & \multirow{3}{*}{0.010} & \multirow{3}{*}{0.033} & 0.25 & 5.2 & -7.7 \\
\hline & & & & & & & 1.0 & 6.2 & 1.4 \\
\hline & & & & & & & 2.5 & 5.0 & -0.2 \\
\hline
\end{tabular}

${ }^{a}$ Resolution (Rs) was the ratio of the separation between two peaks to the average width of the two peaks. ${ }^{b}$ Calibration range corresponding to each enantiomer in racemic standard. ${ }^{c}$ Correlation coefficient. ${ }^{d}$ Limit of detection. ${ }^{e}$ Limit of quantification. ${ }^{f}$ Relative standard deviation for $\mathrm{n}=3$. ${ }^{g}$ Relative error $=\{($ measured mean value - nominal value $) /$ nominal value $\} \times 100$. Bold ions were selected for quantification. All measurements were performed in triplicate. 


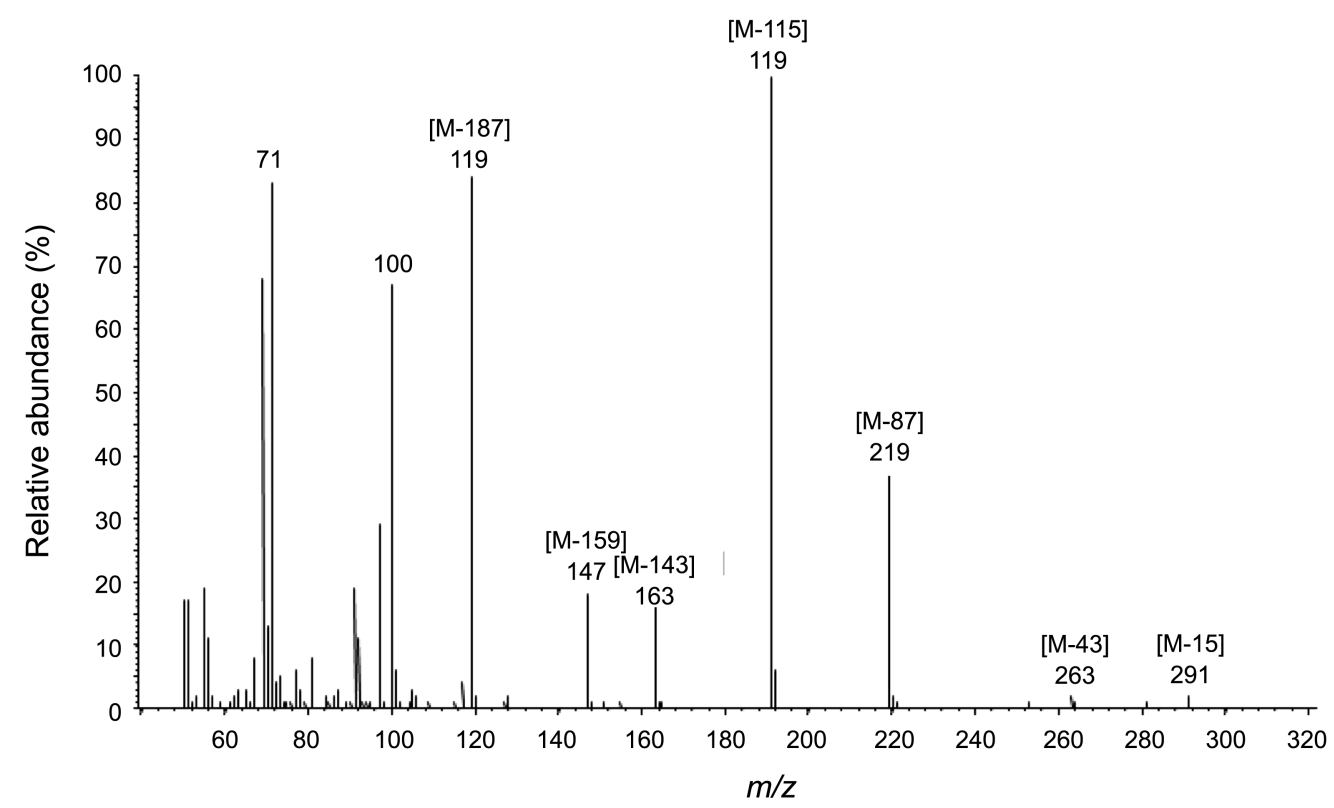

Figure 1. Electron-impact mass spectrum of lactic acid as $O$-pentafluoropropionylated $(S)-(+)$-3-methyl-2-butyl ester.

Next, they were extracted with diethyl ether $(3 \mathrm{~mL})$ and ethyl acetate $(2 \mathrm{~mL})$. The extracted mixtures were evaporated under a gentle nitrogen stream, which were converted into $(S)-(+)$-3-methyl-2-butylation combine with $O$-PFP derivatives as proceeding above.

\section{Results and Discussion}

Diastereomeric (S)-(+)-3-Methyl-2-Butylation and $\boldsymbol{O}$ Pentafluoropropionylation. This reaction involved $(S)-(+)-$ 3-methyl-2-butylation of the carboxyl group and pentafluoropropionylation for the hydroxyl group of lactic acid, which was no evidence for racemization although artifacts showed as trace level.

The mass spectrum of the diastereomeric $O$-pentafluoropropionylated $(S)-(+)-3$-methyl-2-butyl ester of lactic acid was shown in Figure 1. Its derivative was easily identified from its characteristic mass spectrum. The molecular ion of $m / z 306$ was not observed, and a base peak that corresponds to the loss of $\mathrm{COO}\left(\mathrm{CH}_{2}\right)_{2} \mathrm{CH}\left(\mathrm{CH}_{3}\right)_{2}$ was formed at $\mathrm{m} / z 191$. The $[M-87]^{+}$and $[M-143]^{+}$fragment ions were assumed to be formed by the loss of $\mathrm{O}\left(\mathrm{CH}_{2}\right)_{2} \mathrm{CH}\left(\mathrm{CH}_{3}\right)_{2}$ and $\mathrm{CH}_{3} \mathrm{CHCOO}\left(\mathrm{CH}_{2}\right)_{2} \mathrm{CH}\left(\mathrm{CH}_{3}\right)_{2}$ from the molecular ion, respectively. Further, the second most abundant peak was the one corresponding to $\mathrm{CF}_{2} \mathrm{CF}_{3}$, and this peak was formed at $m / z$ 119. The enantiomeric eluting order of lactic acid was shownin Figure 2, which confirmed by addition of $(S)$-lactic acid standard to racemic lactic acid. The enantiomers were completely separated with a resolution of 1.9 by achiral GCMS-SIM analysis (Fig. 2, Table 1). Further, the impurity peaks that correspond to the reagents and solvents did not affect the measurement of the enantiomers.

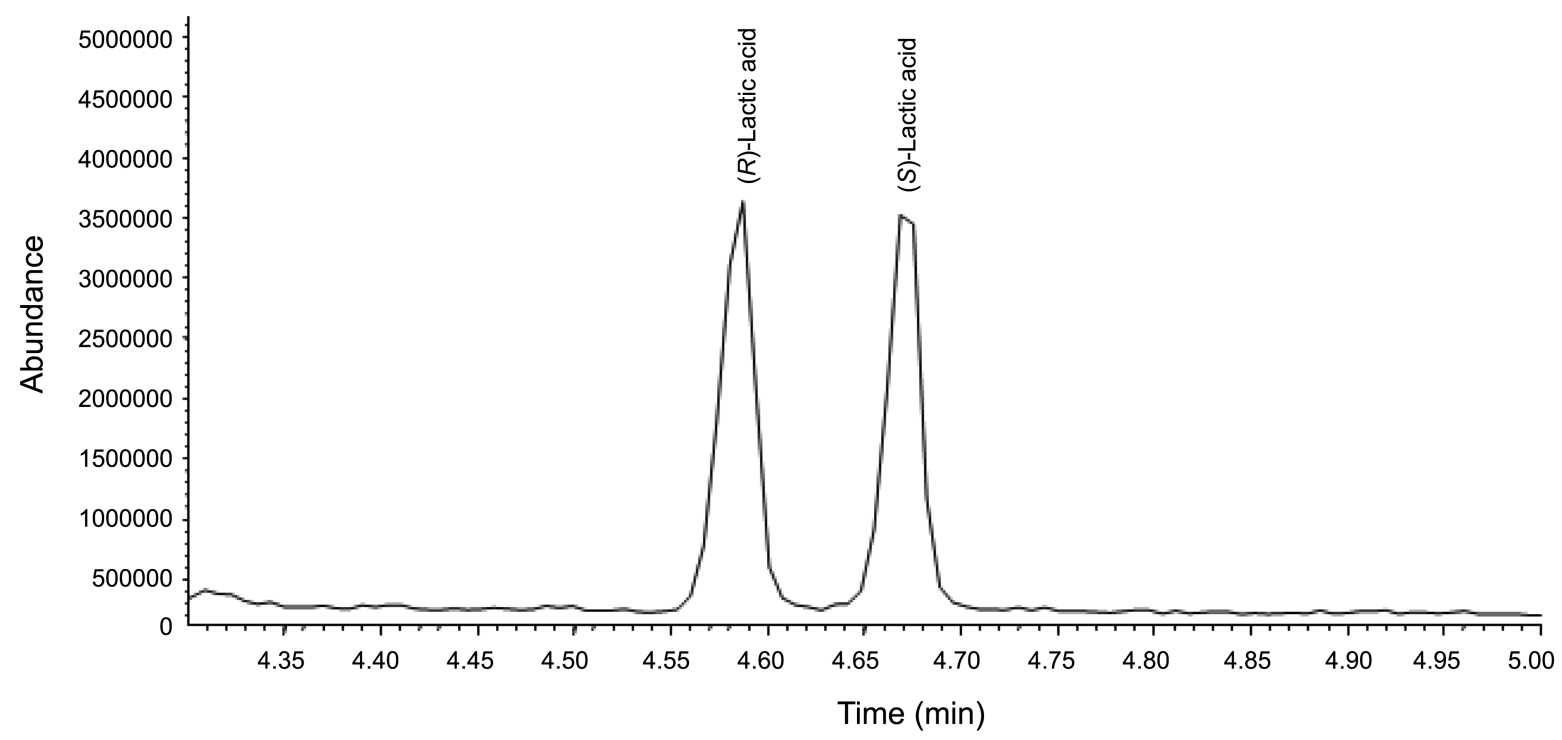

Figure 2. SIM Chromatogram of the lactic acid enantiomers as $O$-pentafluoropropionylated $(S)$-(+)-3-methyl-2-butyl ester. 


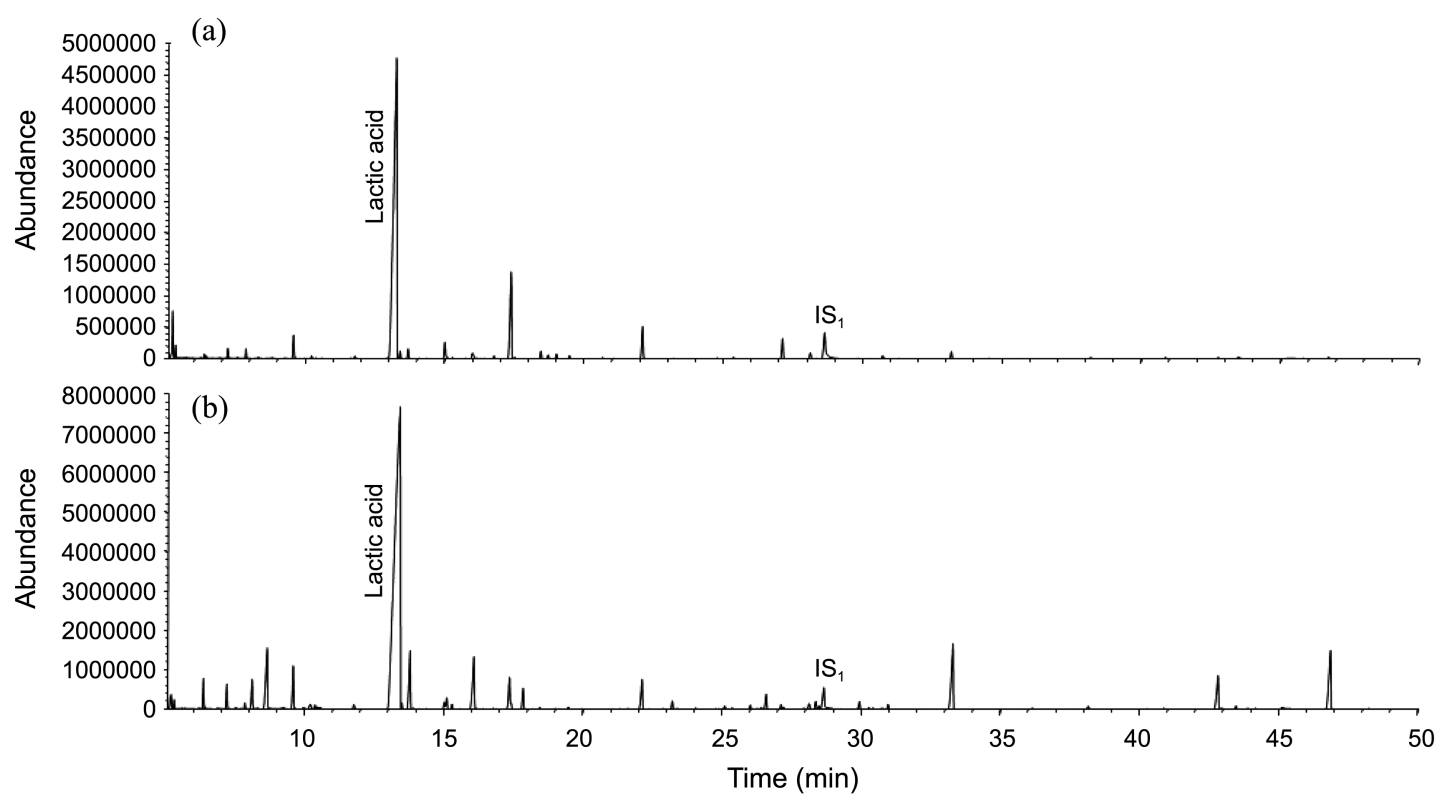

Figure 3. Chromatograms of lactic acid in (A) LAB 304 cells and (B) cell growth media as the form of a racemic tert-butyldimethylsilyl derivative. $\mathrm{IS}_{1}$ : 3,4-dimethoxybenzoic acid.
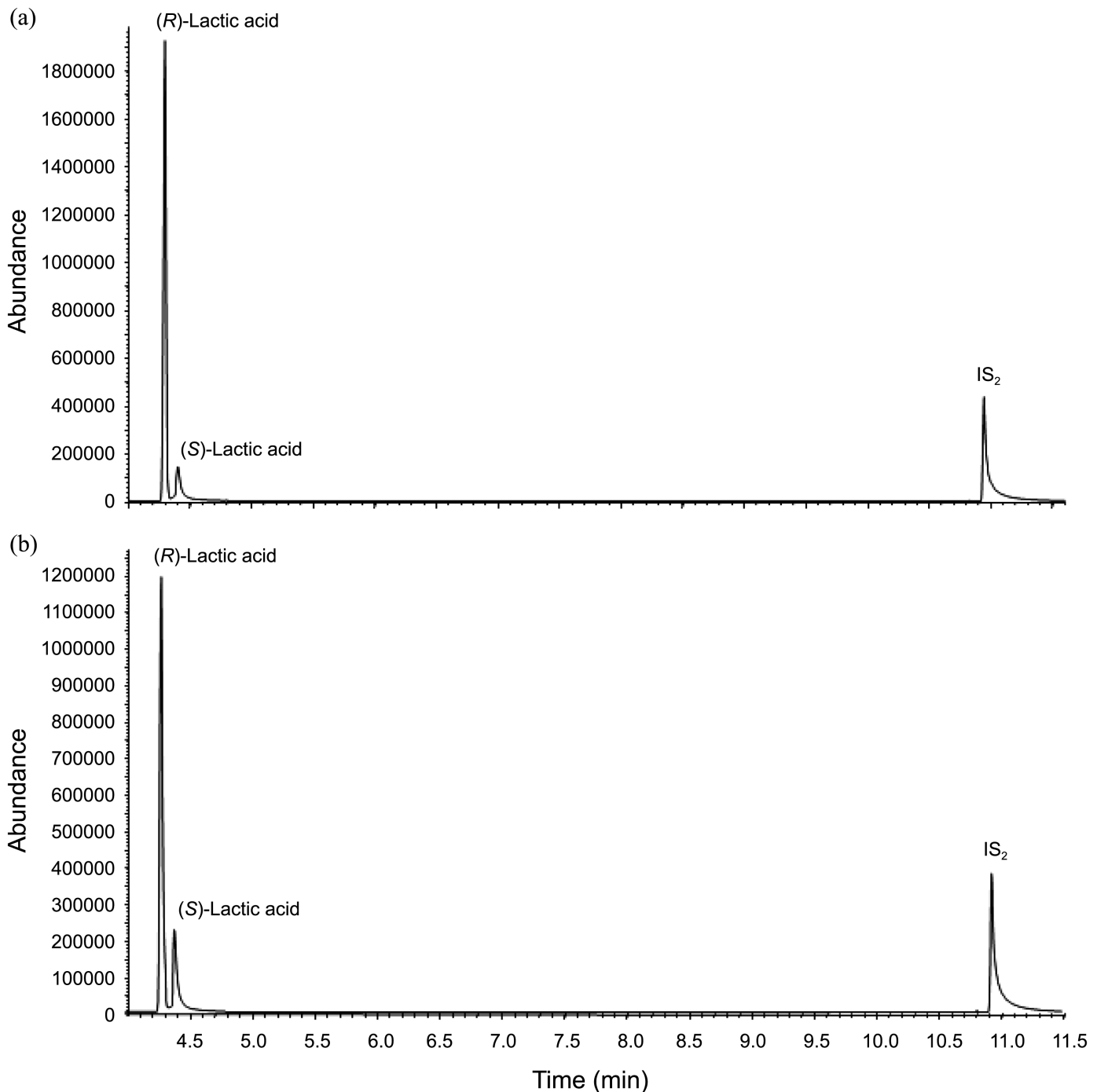

Figure 4. SIM chromatograms of lactic acid enantiomers as diastereomeric (S)-(+)-3-methyl-2-butyl ester in (A) LAB 304 cells and (B) cell growth media. $\mathrm{IS}_{2}: \mathrm{nHC}_{22}$. 
Table 2. Composition (\%) of lactic acid enantiomers as $O$ pentafluoropropionylated $(S)-(+)-3$-methyl-2-butyl ester in LAB 304

\begin{tabular}{lccccc}
\hline \multirow{2}{*}{ Enantiomer } & \multicolumn{2}{c}{ Amount $\pm \mathrm{SD}(\mu \mathrm{g})$} & \multicolumn{2}{c}{ Composition $\pm \mathrm{SD}(\%)^{a}$} \\
\cline { 2 - 3 } \cline { 5 - 6 } & Cells & Media & & Cells & Media \\
\hline$(R)$-Lactic acid & $11.8 \pm 0.7$ & $6.9 \pm 0.2$ & & $89.0 \pm 0.1$ & $78.2 \pm 0.4$ \\
$(S)$-Lactic acid & $1.5 \pm 0.1$ & $1.9 \pm 0.1$ & & $11.0 \pm 0.1$ & $21.8 \pm 0.4$ \\
\hline
\end{tabular}

All measurements were performed in triplicate. ${ }^{a}$ Ratio of amount of $\{(R)$-lactic acid or $(S)$-lactic acid $\} /\{(R)$-lactic acid $+(S)$-lactic acid $\} \times$ 100

Method Validation for Chiral Assay of Lactic Acid in LAB 304 Cells and Cell Growth Media. Under the optimal conditions, enantiomers of lactic acid showed good linearity $(\mathrm{r} \geq 0.999)$ in the range of 0.1 to $15.0 \mu \mathrm{g}$ (Table 1). Moreover, the LOD and LOQ for each enantiomer of lactic acid were 0.011 and $0.036 \mu \mathrm{g}$, respectively. The present method showed lower LOD and LOQ levels than other reported methods, ${ }^{10-12,14}$ which has good MS property for GC-MS analysis than those of our previous methods. ${ }^{6,7}$ Thus, these may explain for usefulness of chiral composition test for various samples containing lactic acid enantiomers of trace level.

The precision and accuracy were 3.4 to 6.0 (\% RSD) and -7.7 to 1.4 (\% RE), respectively. These values prove that this method is suitable for the assay of $(S)$-lactic acid and $(R)$-lactic acid. The derivatives of the lactic acid enantiomers were stable for three weeks when refrigerated and stored in securely sealed vials.

Identification and Chiral Composition of Lactic Acid in LAB 304 Cells and Cell Growth Media. Lactic acid as racemic TBDMS derivative was monitored as the most abundant single peak in cells (Fig. 3(a)) and supernatant of the growth media (Fig. 3(b)).

Quantification of the $(R)$-lactic acid and $(S)$-lactic acid in the cells (Fig. 4(a)) and media (Fig. 4(b)) of LAB 304 was performed by using the present new method. SIM chromatograms of the enantiomers of lactic acid in the cell and medium showed in Figure 4. The amount of $(R)$-lactic acid was higher than that of $(S)$-lactic acid in the cell and medium. The chiral compositions as percentage of $(R)$-lactic acid in cell and media were determined with high precision to be $89.0 \pm 0.1 \%$ and $78.2 \pm 0.4 \%$, respectively (Table 2 ). These chiral compositions in the cells and media show that LAB 304 mainly produces $(R)$-lactic acid. Thus, we verified the usefulness of the present method for chiral discrimination analysis and composition test of lactic acid and other chiral organic acids present in the cells and the growth media of various microorgranisms during the fermentation process.

\section{Conclusion}

The present method based on enantioseparation of lactic acid as diastereomeric $O$-pentafluoropropionylated $(S)-(+)-$ 3-methyl-2-butyl ester by using GC-MS. It was linear ( $\mathrm{r} \geq$ $0.999)$ with acceptable precision (3.4-6.2\%) and accuracy $(-7.7-1.4 \%)$. The results of enantiomeric composition (\%) tests of lactic acid from LAB 304 were 89.0:11.0 (R:S) in cell pellet and 78.2:21.8 $(R: S)$ in supernatant of growth media, respectively. Thus, the present method will be useful for the chiral separation and the optical purity test of lactic acid enantiomers in various microorganisms.

Acknowledgments. This work was supported by the National Research Foundation of Korea Grant funded by the Korean Government (MEST) (NRF-2009-C1AAA001-20090093062).

\section{References}

1. Caligiani, A.; Cirlini, M.; Palla, G.; Ravaglia, R.; Arlorio, M. Chirality 2007, 19, 329.

2. Grabar, T. B.; Zhou, S.; Shanmugam, K. T.; Yomano, L. P.; Ingram, L. O. Biotechnol. Lett 2006, 28, 1527.

3. Joshi, D. S.; Singhvi, M. S.; Khire, J. M.; Gokhale, D. V. Biotechnol. Lett 2010, 32, 517.

4. John, R. P.; Nampoothiri, K. M.; Pandey, A. Appl. Microbiol. Biotechnol 2007, 74, 524.

5. Ewaschuk, J. B.; Zello, G. A.; Naylor, J. M.; Brocks, D. R. J. Chromatogr. B 2002, 781, 39.

6. Kim, K. R.; Lee, J.; Ha, D.; Jeon, J.; Park, H. G.; Kim, J. H. J. Chromatogr. A 2000, 874, 91.

7. Kim, K. R.; Lee, J.; Ha, D.; Kim, J. H. J. Chromatogr. A 2000 , 891, 257.

8. Inoue, Y.; Shinka, T.; Ohse, M.; Kohno, M.; Konuma, K.; Ikawa, H.; Kuhara, T. J.Chromatogr. B 2007, 855, 109.

9. Inoue, Y.; Shinka, T.; Ohse, M.; Ikawa, H.; Kuhara, T. J. Chromatogr. B 2006, 838, 37.

10. Ewaschuk, J. B.; Naylor, J. M.; Barabash, W. A.; Zello, G. A. J. Chromatogr. B 2004, 805, 347.

11. Norton, D.; Crow, B.; Bishop, M.; Kovalcik, K.; George, J.; Bralley, J. A. J. Chromatogr. B 2007, 850, 190.

12. Franco, E. J.; Hofstetter, H.; Hofstetter, O. J. Pharm. Biomed. Ana. 2009, 49, 1088.

13. Maier, V.; Petr, J.; Knob, R.; Horakova, J.; Sevcik, J. Electrophoresis 2007, 28, 1815.

14. Tana, L.; Wang, Y.; Liu, X.; Ju, H.; Li, J. J. Chromatogr. B 2005, $814,393$.

15. Paik, M. J.; Kim, K. R. J. Chromatogr. A 2004, 1034, 13.

16. Paik, M. J.; Lee, H. J.; Kim, K. R. J. Chromatogr. B 2005, 821, 94.

17. Paik, M. J.; Moon, S. M.; Kim, K. R.; Choi, S.; Ahn, Y. H.; Lee, G. Biomed. Chromatogr. 2008, 22, 339. 